spread of the disease among the other boys. The privies at present are extremely primitive; their contents fall directly into a running stream, which passes through the college grounds, and which in many places passes directly under the college buildings. This stream is derived from a larger, known as Lower Brook, which passes as an open sewer directly past the college gates; this Lower Brook practically receives the sewage of half the lower part of the town of Winchester. We understand the sohool authorities intend to provide earth-closets instead of the present privies, and also to divert the course of the stream passing through the college grounds; but we fear it will be impossible to restrain the town authorities from continuing to permit pollution of the Lower Brook, which must remain for some time to come an unsafe and unpleasant neighbour. The urinals in the college premises might be improved with advantage. The water-supply of the college is derived from two sources: the first and most used is the water supplied by the town water-works, which is of excellent quality, and is taken from a deep well in the chalk, and there is no danger of its becoming polluted; the other, which supplies the kitchen, jointly with the other service, is derived from the other side of the river, and we were not sure but that at times it might receive chance contamination, and we should advise its discontinuance. The college buildings are situated on the broad meadows which intervene between the river and the foot of the chalk downs, on which the principal part of the town is built. The soil consists of a bed of gravel and peat, about eighteen feet in depth, resting on the chalk. From the lowness of the situation, and from damming back of the river by the numerous mill heads, which hinders the natural drainage, the playing. grounds are not so dry as they ought to be. This should be remedied by artificial drainage, so as quickly to carry off the surface water. The school premises are situated quite at the outskirts of the town, and, if it were not for the abominable Lower Brook, would be quite independent of it with respect to sanitary matters.

The commoners reside in boarding-houses kept by the masters. The chief house belongs to the head master, and is situate in close proximity to the college buildings; and the sanitary arrangements and conditions are much the same. The houses of the other masters are nearer the town. These houses were private property, and no supervision was exercised over their arrangements. Now the governing body, in order to secure uniformity of management and a thoroughly good sanitary condition, have determined to buy up these houses, and relet them to the masters under certain specified conditions. In the houses that have, up to this time, been purchased by the governing body considerable improvements have been effected, and some are perfect models of construction and arrangement. The system of earth-closets has been generally introduced, and the system is to be extended to all the other houses and to the college buildings. Schoolmasters, who may be desirous of isolating their school from a defective and im. perfect town drainage, should visit the new boarding. houses at Winchester and see the admirable manner in which the system is carried out. The domestic arrangement at the boarding-houses is excellent, and the diet good and abundant.

There is no regular medical supervision. There are three doctors nominally attached to the school, and the house master chooses which he prefers, when there is actual illness in his house. No regular medical certificate is required on a boy's entering the school, having reference to his physical condition and the nature of his previous illnesses, and it is left to the discretion of the house master to make such inquiries; nor are the parents required to furnish any certificate declaring that the boy has been free from zymotic disease, or been brought in contact with such disease during the holidays. There is no medical inspection on the boy's return to school, so that ringworm, scabies, scarlet fever, \&c., might readily be introduced if any parent ignorantly or wilfully returned a boy suffering from such diseases back to scbool. As the boys only come under the care of the medical men when suffering from actual illness, nothing can be known of the actual condition of a boy prior to such illness. We have shown at Marlborough how excellently the system of medical supervision is worked there, and the advantages that the school has derived from it; how in many instances cases of actual breakdown have been avoided, and how, by timely removal for a term or so, a boy has been able to tide over his school career satisfactorily. We think the governing body at Winchester ought to adopt some such system. With the services of three medical men at their command, there could be no difficulty in having the foregoing particulars attended to, and a supervision as thorough as that of Marlborough instituted. The arrangement of the dormitories at Winchester is excellent. These contain, on an average, nine beds for boys of all ages; there is also a general sitting-room in each house, and a few studies for the senior boys. The hours of work are not excessive: two days a week a boy is in school six or seven hours, on other days four or five; sixth-form boys, however, when preparing for an examination may spend eight or nine hours; all lessons, as a rule, are prepared in the school-room. The system of fagging is more fully carried out at Winchester than at the other public schools, and even here it has been greatly modified of late years. The system is somewhat complicated, and it is diffcult to understand the details. We could not learn, however, that it was in any way injurious to a boy who was fitted to be at a public school at all. We know that many parents object to the system, but we think, if carried out with proper supervision, it serves as a restraint in some measure to the growing luxury of schoolboy life, and taking the opinion of "fags" generally, we think it would be found they themselves are not at all averse to it.

In conclusion, we are able to state that the sanitary arrangements and condition of the school at Winchester are, on the whole, satisfactory (we wish we could say the same of the town), and show a marked improvement in this respect to its state some few years back, when it had a very bad reputation for ill-health; so much so, that the commoners in 1858 were reduced in number to 68 . The fact that in the last ten years there have been only two deaths from zymotic disease in the whole school, and that no outbreak of scarlet fever has occurred now for some years, though several cases have been imported, and a serious epidemic occurred in the town about two years ago, speaks very favourably for the general management. The arrangement of the dormitories is most judicious; the number of beds is sufficiently large to afford protection against the possibility of immoral practices being even secretly carried out, whilst the number is not so great as to cause danger from the spread of zymotic disease casually introduced. What Winchester most requires is a thorough and complete system of medical supervision. Many of the younger schouls have long since recognised the importance of this, and we feel convinced that Winchester cannot much longer delay following their example.

\section{THE NEW HUMAN FLUKE.}

\section{To the Editor of The LANCET.}

$\mathrm{SIR}_{3}$-Professor McConnell's description of another human fluke, as given in your pages for August 21st, is of such high interest to helminthologists that I trust you will permit me space enough to say a few words on the subject. Without doubt the species is new to science, and ought to have some distinctive name by which it may be recognised amongst the trematodes. I propose to call it Distoma sinense. The evidence adduced by Dr. MoConnell in proof of the specific distinctness of his entozoon is overwhelming, and his account of the parasite's anatomical structure presents features of special import. In regard, however, to the flukes obtained by Dr. J. G. Kerr, I have no doubt that they will turn out to be thoroughly characteristic examples of Prof. Busk's Distoma crassum, the opinion of Prof. J. Leidy (who so well describes the parasites) to the contrary notwithstanding. In the fortheoming issue of the Journal of the Linnean Society there will be a description of two more instances of the occurrence of Busk's fluke in the human subject, founded on specimens obtained from a missionary and his wife who placed themselves under the professional care of Dr. George Johnson and myself. Prof. McConnell's fluke is quite distinct from all the other human and animal trematodes at present known to science, and to this extent, therefore, the case is unique. I am, Sir, yours truly,

Harley-street, Sept. 2nd, 1875. T. SPEncer Cobbold. 